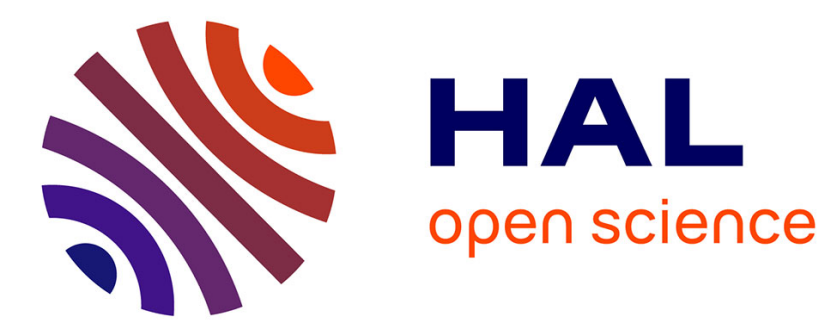

\title{
Performance factors in the new combined event of modern pentathlon
}

Yann Le Meur, Christophe Hausswirth, Chris Abbiss, Yann Baup, Sylvain

Dorel

\section{- To cite this version:}

Yann Le Meur, Christophe Hausswirth, Chris Abbiss, Yann Baup, Sylvain Dorel. Performance factors in the new combined event of modern pentathlon. Journal of Sports Sciences, 2010, 28 (10), pp.11111116. 10.1080/02640414.2010.497816 . hal-01724303

\section{HAL Id: hal-01724303 https://hal-insep.archives-ouvertes.fr/hal-01724303}

Submitted on 6 Mar 2018

HAL is a multi-disciplinary open access archive for the deposit and dissemination of scientific research documents, whether they are published or not. The documents may come from teaching and research institutions in France or abroad, or from public or private research centers.
L'archive ouverte pluridisciplinaire HAL, est destinée au dépôt et à la diffusion de documents scientifiques de niveau recherche, publiés ou non, émanant des établissements d'enseignement et de recherche français ou étrangers, des laboratoires publics ou privés. 


\title{
Performance factors in the new combined event of modern pentathlon
}

\author{
Yann Le Meur ${ }^{1}$, Christophe Hausswirth ${ }^{1}$, Chris Abbiss ${ }^{2}$, Yann Baup ${ }^{1}$, Sylvain Dorel ${ }^{1}$ \\ 1 National Institute of Sport, Expertise and Performance (INSEP), Paris, France \\ 2 School of Exercise, Biomedical and Health Sciences, Edith Cowan University, Joondalup, WA, Australia
}

Publié dans : Journal of Sports Sciences, 2010, vol. 28, $n^{\circ} 10$, pp. 1111-1116

(DOI : 10.1080/02640414.2010.497816)

\begin{abstract}
To determine the individual tactics employed by elite modern pentathletes within each discipline of the new combined running-shooting event, and the consequences of these strategies on the overall performance. 36 male pentathletes competing in a world cup event, where running velocity, transition time, shooting time, shooting accuracy and delay per shot were measured. Performances of the top third pentathletes (TOP), the middle third pentathletes (MIDDLE) and the bottom third pentathletes in the combined event (BOTTOM) were compared. The difference in overall performance between TOP and MIDDLE/BOTTOM was predominately associated with a better shooting accuracy ( $79 \pm 13 \%, 68 \pm 12 \%$ and $64 \pm 10 \%$ success rate, for TOP, MIDDLE, BOTTOM, respectively) and a quicker shooting time ( $86 \pm 16 \mathrm{~s}, 109 \pm 19$ s and $117 \pm 23 \mathrm{~s}$, for the TOP, MIDDLE, BOTTOM, respectively). No significant difference was observed on running velocity, transition time and delay per shot among the three groups. All the competitors started significantly faster over the first $200 \mathrm{~m}$ of each of the three $1 \mathrm{~km}$ running stages. The last third of the approximately $3 \mathrm{~km}$ race was completed significantly faster by all pentathletes $(p<0.05)$. The main finding was that the best performers of the combined event distinguished themselves due to their greater shooting accuracy.
\end{abstract}

\section{INTRODUCTION}

The Modern Pentathlon is an Olympic sport, which comprises of pistol shooting, fencing, swimming, horse riding and running events, all of which are completed in a single day. A points system for each discipline is based on a standard performance earning 1000 points. Until recently, the fifth and final event was a $3 \mathrm{~km}$ run performed with a handicap start based on the athletes' total points from the first four events. Since 2009, the "Union Internationale de Pentathlon Moderne" (UIPM) decided that the shoot and run disciplines will be completed simultaneously in a combined event following the fence, swim and ride disciplines. Pentathletes begin the final event as per the previous handicap system, with a short run to the shooting range, where they are required to shoot 5 targets down in less than 70 seconds and with an unlimited number of shots, by loading the gun after each attempt. Following this, the athletes are required to run approximately $1 \mathrm{~km}$. If after 70 seconds one of the 5 targets or more has (have) not been hit, the pentathlete can start the next running leg without being further penalised. They repeat this combination 
further two times, in total shooting 15 targets and running approximately 3-km. This new rule may affect the demands of shooting and running for elite pentathletes.

Several studies focusing on multisport events like triathlon (Hausswirth \& Brisswalter, 2008), duathlon (Vallier et al., 2003) and biathlon (Hoffman et al., 1992a,b) have demonstrated that the sequential order of events may result in specific physiological and cognitive demands, which differentiate them from each event considered individually. In this perspective, biathlon shares many similarities with the new combined event of modern pentathlon as it combines a highly energetic locomotive activity (i.e. crosscountry skiing) and a precision shooting task (i.e. rifle marksmanship) (Hoffman et al., 1992a,b). Performance in biathlon is dependent upon maximizing the locomotion velocity and shooting accuracy, and minimizing the time spent at the firing line. Hoffman et al. (1992a) demonstrated that exercise intensity affects both shooting accuracy and precision for standing shooting and that biathletes may benefit from reducing the skiing velocity while approaching the firing range before shooting in the standing position. In modern pentathlon, no data relating to the individual tactics employed and skills within each discipline of the new shooting-running combined event and the consequences on the overall performance has yet been made available.

The purpose of the present study, therefore, was to quantify the running velocity and shooting performance in a population of elite pentathletes competing in an UIPM World Cup event. In particular we sought to determine the influence of both running and shooting disciplines on overall race performance and determine whether better performers adopt different shooting and pacing strategies, compared with less successful competitors.

\section{METHODS}

\section{Participants}

Thirty-six elite male pentathletes were involved in the present study. They were all competing in the UIPM and their world ranking ranged between 3 and 79 at the end of season 2008. The experimental methodology was performed in accordance with the Declaration of Helsinki.

\section{Procedures}

Each participant was examined during both running and shooting stages of the final of an international modern pentathlon competition (Budapest UIPM World Cup, Hungary,

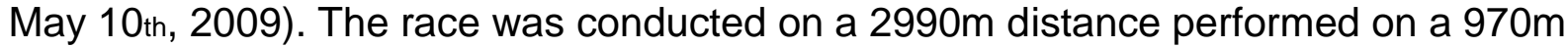
flat loop covered three times (cumulative climb of $3 \mathrm{~m}$ in the total course). Each lap comprised a $20 \mathrm{~m}$ run section, a $70 \mathrm{~m}$ length firing-area and a $900 \mathrm{~m}$ run section. The final lap was extended by an $80 \mathrm{~m}$ section to the finish line. The circuit exhibited several changes of direction (eight $90^{\circ}$-turns over the asphalt/grass section [90-300m], two $90^{\circ}$ and one $180^{\circ}$ - turns over the asphalt section [300-600m] and two $90^{\circ}$-turns over the grass section [600-970m]). Grass sections were hard and not slippery. The three shooting rounds (i.e. standing position) were disposed on a 70-m length firing area with individual shooting boxes. Electronic targets (EasyTargets $\odot$, Competition Level A, Easypenta, France) were composed by one black single aim and 5 green/red lamps to indicate the number of remaining successful shots. The competitors were required to hit 5 times the single target of $250 \mathrm{~mm}$ diameter within a $59.5 \mathrm{~mm}$ diameter. Targets were 
situated at $10 \mathrm{~m}$ from the firing line. Except the obligation to hold the pistol with only one hand, the shooting position was left free according to UIPM rules. Each pentathlete used his own pistol, which was deposited in his box after each shooting session. The latter had to be placed on the table pointing targets, unloaded in an open position.

Running phases. A video analysis system recording at a frequency of $25 \mathrm{~Hz}$ (Sony HDRCX12 AVHD) was synchronized with the official timing system (Omega, Swatch Group, Swiss). The video analysis system included five digital cameras located at the exit of the firing line $(90 \mathrm{~m})$, at $300,620,900 \mathrm{~m}$ and at the entrance of the shooting range $(970 \mathrm{~m})$. Distances between these points were measured using both a measuring wheel (Debrunner, Givisiez, art. 851.236) and a global positioning system, with an accuracy of 2 - 3 meters (GPS, Garmin GPSRAP 60CSx, Garmin Europe, United Kingdom).

Shooting sessions. Targets were equipped with a sensing receptor, which was activated when pentathletes succeeded in hitting the target (EasyTargets $\odot$, Competition Level A, Easypenta, France). The trigger of each pistol was similarly connected to an electronic pressure-sensitive system, which was activated at each shot (EasyTargets $\odot$, Competition Level A, Easypenta, France). These values issued from both targets and pistols were timesynchronized and recorded at a sampling rate of $100 \mathrm{~Hz}$ on the same computer. Official records from the digital targets were used to measure the shooting accuracy (i.e. rate of success in hitting the five targets during each shooting session as a percentage), the shooting time (i.e. the global delay between the first and the last shot of the three shooting sessions) and the shooting delay per attempt (i.e. the mean period of time between two consecutive shots). All the variables were considered for each running lap or each shooting session individually and also pooled for the entire race. The transition time on the shooting range was also calculated by deducting the shooting time from the time spent on the shooting range.

\section{Data processing}

The elapsed time (s) for each section, each lap and the entire circuit was determined for each athlete from the race timing system and video data. Running velocity (km.h-1) of each athlete was determined via a subsequent video analysis (Pro suite version 5.0, Dartfish ${ }^{\circledR}$, Fribourg, Swiss) for the following sections: [90m-300m], [300m-600m], [600m-900m], [900m-970m] for each lap and between $970 \mathrm{~m}$ and $1050 \mathrm{~m}$ for the last lap. For further analyses, pentathletes were grouped into a top third (TOP, $n=12$ ), a middle third (MIDDLE, $n=12$ ) and a bottom third (BOTTOM, $n=12$ ) according only to their combined event ranking.

\section{Statistical analysis}

All data were expressed as mean \pm standard deviation (SD). These data were pooled considering the sections previously described. A one-way ANOVA was conducted to determine the effect of performance level during the combined event (i.e. top, middle and bottom thirds) on final ranking of the world cup, mean running velocity, mean transition time, mean shooting accuracy, and mean shooting delay per attempt, when considering the whole combined event. A two-way ANOVA ( 3 performance levels $\times 3$ laps) was carried out using running velocity, transition time, shooting accuracy and shooting delay per attempt. Where significant effect was observed, a Tukey's post-hoc 
test was conducted to further delineate differences between populations and laps. Pearson's product moment correlations were used to determine the relationships between the overall ranking of the world cup and each discipline (i.e. swimming, fencing, riding and the combined event). For analysis, significance was accepted at $P<0.05$. All statistical analysis was conducted using Origin 8.0 software (OriginLab $\AA$, Northampton, MA, USA).

\section{RESULTS}

Overall performance. The top third pentathletes in the combined event demonstrated a significant better final ranking (i.e. overall ranking of the world cup) than the bottom third (10 \pm 8 vs. $21 \pm 8$, for TOP and BOTTOM, respectively, $\mathrm{P}<0.05$ ) but not than middle third ( $10 \pm 8$ vs. $15 \pm 9$, for TOP and MIDDLE, $P>0.05)$. Coefficients of correlation between overall ranking of the world cup and each disciplines are presented in Table 1.

\section{${ }^{\star \star \star \star}$ Table 1 near here ${ }^{\star \star \star \star}$}

Running performance. Table 2 presents running performance (total running time and running velocity) for the three groups. There was no difference in average running velocity among the three groups $(P=0.95, P=0.13$ and $P=0.21$, when considering TOP vs. MIDDLE, TOP vs. BOTTOM and MIDDLE vs. BOTTOM, respectively).

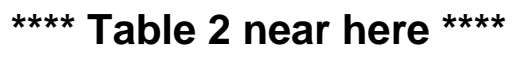

A significantly higher running velocity was observed during the last lap compared with lap1 and lap2 in all three groups $(P<0.05$, Figure 1$)$. Likewise, the velocity over the first section (i.e. between $90 \mathrm{~m}$ and $300 \mathrm{~m}$ for each lap) was systemically higher than the other sections in all three groups $(P<0.05$, Figure 2$)$. On the contrary, no significant difference was observed between section [600-900m] and section [900-970m] (i.e. approach of the firing line, $P>0.05$, Figure 2 ). A significantly higher running velocity was observed in all three groups over the final $80-\mathrm{m}$ of the race $(P<0.05)$.

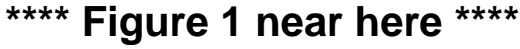

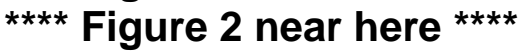

Shooting performance. Shooting performances (i.e. total shooting time, overall shooting accuracy and mean delay per shot) during the entire race are presented in Table 2. The global shooting time was significantly related to the shooting accuracy $(r=$ $0.71, P<0.01)$ but not related to the shooting delay $(P>0.05)$. Top third pentathletes in the combined event needed significantly less attempts to shoot the 15 targets, compared with the middle and the bottom ones (19 \pm 3 shots vs. $22 \pm 4$ shots and $23 \pm 4$ shots, for TOP, MIDDLE and BOTTOM, respectively, $\mathrm{P}<0.05$ ). On the other hand, the middle third in the combined event did not demonstrate higher shooting accuracy than the bottom third in either overall or isolated shooting sessions $(P>0.05)$. Shooting accuracy for the three groups during each shooting session is presented in Figure 3. No significant difference was observed for both total transition time and delay per attempt between the three shooting sessions among the three groups $(P>0.05$, Table 2$)$. 
${ }^{\star \star \star \star}$ Figure 3 near here ${ }^{\star \star \star *}$

\section{DISCUSSION}

The purpose of the present study was to characterise the influence of both shooting and running on the overall race performance and determine if better performers during this combined running-shooting event of a Modern Pentathlon World Cup (i.e. top third) adopted a different strategy, compared with less successful competitors. The main finding of the present investigation was that the best performers possessed greater shooting accuracy resulting in less shooting time than middle and bottom thirds pentathletes in the combined event.

The present results revealed a significant correlation between the combined event ranking and the overall ranking of the competition $(r=0.55, P<0.001$, Table 1$)$. It is interesting to note that this was higher than the coefficients of correlation between overall ranking and ranking in swimming and fencing. Riding performance had the highest influence on overall performance, probably because of the deleterious consequences of the penalties imposed to pentathletes when the horse knocked an obstacle down or stepped back.

Interestingly, no difference in running time was observed between the top, the middle and the bottom thirds pentathletes in the combined event $(P>0.05$, Table 2). Likewise, the mean transition time was similar between the three groups $(P>0.05$, Table 2$)$. As a result it appears that run velocity and transition time did not distinguish top performers from other pentathletes of the field. Instead, the main determining factor of performance distinguishing the top third pentathletes from the other competitors was the global shooting time. Indeed, the total shooting time of the best performers during the combined event (i.e. top third) was $23 \mathrm{sec}$ and $31 \mathrm{sec}$ better than the middle and the bottom thirds in the combined event $(P<0.05$, Table 2$)$. Nevertheless, when compared with the middle and the bottom thirds pentathletes in the combined event there was no trend for the top third to shoot faster $(4.5 \pm 0.4 \mathrm{sec} v \mathrm{vs} .5 .0 \pm 0.7 \mathrm{sec}, \mathrm{P}=0.15$ and $4.5 \pm$ $0.4 \mathrm{sec}$ vs. $5.0 \pm 0.4 \mathrm{sec}, \mathrm{P}=0.18$ for TOP, MIDDLE and BOTTOM, respectively, Table 2). Difference in total shooting time was explained by a higher overall shooting accuracy for the top pentathletes in the combined event than the others competitors in the field (Table 2).

Since differences in shooting performance were evident during the first shooting session $(P<0.05$, Figure 3$)$, which was only preceded by a $20-\mathrm{m}$ run, the higher shooting performance of the top third pentathletes in the combined event seemed to be more closely associated with a greater intrinsic shooting level rather than a greater capacity to overcome the possible detrimental effects of fatigue induced by running. Indeed, the significant difference reported during the first shooting session was no longer significant during the second and the third shooting session $(P>0.05$, Figure 3$)$. Furthermore, the results strengthened the lack of a possible deleterious effect of a running related fatigue on shooting accuracy, as no group decreased its own shooting performance or increased the delay per attempt during the two last sessions in comparison with the first one $(P>0.05)$. The middle third of competitors in the combined event demonstrated no significant difference with the bottom third in shooting and running times (Table 2).

Nevertheless, the combination of no significant lower values for these parameters for the 
middle third (vs. the bottom) resulted in a significant lower overall combined event time in comparison with the bottom third pentathletes $(P<0.05)$. These findings demonstrated that the main determining factor of success during the new runningshooting combined event of UIPM World Cup may differ according to the competitor level. This finding could have clear training implications but needs to be confirmed by future investigations.

The present study provided a description of pacing strategy adopted by elite pentathletes during the combined event of a UIPM World Cup. From these data it was observed that all the competitors adopted a similar "negative pacing strategy" (i.e. negative-split, Abbiss \& Laursen, 2008) over the duration of the race. With no exception $(n=36)$, all pentathletes ran the last lap significantly faster than the first and second laps (Figure 1). This tactic may be associated with the notion that reducing running velocity over the sections preceding shooting may result in a better shooting performance by reducing possible deleterious effects of fatigue associated with a higher running intensity. Supporting this, Hoffman et al. (1992) showed that the intensity of exertion influences standing shooting performance of elite biathletes by altering the stability of the hold. This strategy spontaneously adopted by pentathletes may explain the absence of significant difference in shooting accuracy across the three shooting sessions for each of the three groups. Additionally we reported no difference in running velocity between the two sections preceding the entrance into the shooting range, irrespective of group and shooting session (Figure 2). Conversely, Hoffman and Street (1992b) have reported that biathletes decrease their skiing velocity prior to reaching the shooting range in order to decrease both cardiac and ventilatory demands while shooting. Therefore, unlike elite biathletes, pentathletes did not decrease their running velocity at the approach of the firing line. In the other hand, the present results demonstrated that pentathletes increased significantly their running velocity over the last lap (Figure 1). This final increase in running velocity (i.e. "endspurt") supported that the pacing strategy was continuously altered throughout the event, possibly in response to changing afferent signals but also to reduce the deleterious effects of fatigue on shooting. The relationship between pacing strategy and shooting performance in the combined event of modern pentathlon should be determined in further investigations. A consensus between pacing over the three running sections and the shooting performance should be determined. The present results also revealed that pentathletes systemically adopted a fast start over each run leg despite the circuit comprising of more changes in direction prior to the first timing split, compared with other run sections (Figure 2). In fact, the mean difference in running velocity between the two first running sections of a lap reached $-2.7 \mathrm{~km} . \mathrm{h}-1$ or $13.7 \%$ for the 36 pentathletes (- $2.8 \mathrm{~km} . \mathrm{h}-1$ and $15.7 \%$ for lap $1,-2.6 \mathrm{~km} . \mathrm{h}-1$ and $14.6 \%$ for lap2, $-2.7 \mathrm{~km} . \mathrm{h}-1$ and $11.0 \%$ for lap3, $\mathrm{P}<0.01$ ). Previous studies have reported a similar pacing strategy during the running leg of short distance triathlons (Vleck et al., 2006, 2008; Le Meur et al., 2009). However, the benefit of this positive pacing strategy (i.e. positive split) which is systematically adopted by elite triathletes still remains unclear and has been questioned by several authors (Millet \& Vleck, 2000; Vleck et al., 2006, 2008; Le Meur et al., 2009). It has been suggested that under stable external conditions (i.e. environmental and geographic), a fast start is detrimental in prolonged locomotive events lasting more than 2 minutes such as running (Billat et al., 2001), swimming (Thompson et al., 2003) and cycling (Wilberg \& Pratt, 1988). Hausswirth et al. (2010) demonstrated that elite triathletes increased their running performance by reducing the 
freely-chosen pace, which they used to adopt over the first run kilometre of short distance triathlons. To our view, the fast start systematically observed in the present competition might have been related to the cardiovascular recovery associated with each shooting session. Hoffman and Street (1992b) have shown that heart rate of elite biathletes decreased by $17 \%$ (i.e. $28 \mathrm{bpm}$ ) over the standing shooting period, whereby shooting duration was similar to that of the present study ( $46 \pm 10 \mathrm{sec}$ and $54 \pm 12 \mathrm{sec}$, for Hoffman and Street study and the present one, respectively). Thus, as a result of a reduction in cardiac and ventilatory strain during the shooting sessions, pentathletes may have initially overestimated the pace they would be able to maintain over each isolated run. The necessity to decrease running velocity after $300 \mathrm{~m}$ could have been strengthened by the numerous changes of direction imposed by the initial section of the running circuit (i.e. 8 turns over [90-300m]). It might have led to both high physiological and muscular demands over this section, resulting in fast rise in RPE and to the subsequent slowdown. Such circuit design could have also perturbed the determination of an "optimal" initial running velocity by inducing frequent variations in running velocity. Furthermore the slowdown reported after $300 \mathrm{~m}$ during each lap might have been adopted by pentathletes to reduce the deleterious effects of running on their subsequent shooting performance. This hypothesis was strengthened by the lack of significant difference in shooting accuracy throughout the three shooting sessions and the significant increase in running velocity over the last lap. Further research is needed to determine if pentathletes would benefit from managing their pace more evenly over each running leg.

\section{CONCLUSIONS}

The present study demonstrated that elite pentathletes of the new running-shooting combined event distinguish themselves from the other competitors due to a better shooting accuracy. This research also provided new insights into the strategies that pentathletes use both during running and shooting. Whilst the data from this study give meaningful information for coaches and athletes concerning the demands of the new combined event in modern pentathlon, further studies are required in order to determine the best pacing strategy to adopt over each running leg and over the total race. Future data examining female modern pentathletes would be also of great interest.

\section{REFERENCES}

Abbiss, C.R. \& Laursen, P.B. (2008). Describing and understanding pacing strategies during athletic competition. Sports Medicine, 38, 239-52.

Billat, V.L., Slawinski, J., Danel, M. \& Koralsztein, J.P. (2001). Effect of free versus constant pace on performance and oxygen kinetics in running. Medicine and Science in Sports and Exercise, 33, 2082-8.

Hausswirth, C. \& Brisswalter, J. (2008). Strategies for improving performance in long duration events: Olympic distance triathlon. Sports Medicine, 38, 881-91.

Hausswirth C, Le Meur Y, Bieuzen F, Bernard T, Brisswalter J (2010) Pacing strategy during the initial phase of the run in triathlon: influence on overall performance. European Journal of Applied Physiology, 108, 1115-23. 
Hoffman, M.D., Gilson, P.M., Westenburg, T.M. \& Spencer, W.A. (1992a). Biathlon shooting performance after exercise of different intensities. International Journal of Sports Medicine, 13, 270-3.

Hoffman, M.D. \& Street, G.M. (1992b). Characterization of the heart rate response during biathlon. International Journal of Sports Medicine, 13, 390-4.

Le Meur, Y., Hausswirth, C., Dorel, S., Bignet, F., Brisswalter, J. \& Bernard, T. (2009). Influence of gender on pacing adopted by elite triathletes during a competition. European Journal of Applied Physiology, 106, 535-45.

Millet, G.P. \& Vleck, V.E. (2000). Physiological and biomechanical adaptations to the cycle to run transition in Olympic triathlon: review and practical recommendations for training. British Journal of Sports Medicine, 34, 384-90.

Thompson, K.G., MacLaren, D.P., Lees, A. \& Atkinson, G. (2003). The effect of even, positive and negative pacing on metabolic, kinematic and temporal variables during breaststroke swimming. European Journal of Applied Physiology, 88, 43843.

Vallier, J.M., Mazure, C., Hausswirth, C., Bernard, T. \& Brisswalter, J. (2003). Energy cost of running during a specific transition in duathlon. Canadian Journal of Applied Physiology, 28, 673-84.

Vleck, V.E., Burgi, A. \& Bentley, D.J. (2006). The consequences of swim, cycle, and run performance on overall result in elite Olympic distance triathlon. International Journal of Sports Medicine, 27, 43-8.

Vleck, V.E., Bentley, D.J., Millet, G.P. \& Bürgi, A. (2008). Pacing during an elite Olympic distance triathlon: comparison between male and female competitors. Journal of Science and Medicine in Sport, 11, 424-432.

Wilberg, R.B. \& Pratt, J. (1988). A survey of the race profiles of cyclists in the pursuit and kilo track events. Canadian Journal of Sport Sciences, 13, 208-13.

TABLE 1. Correlation matrix between the ranking for each event considered individually and the final overall ranking of the World Cup for all modern pentathletes of the race $(n=36)$.

\begin{tabular}{|c|c|c|c|}
\hline $\mathbf{r}_{\text {Swim }}$ & $r_{\text {Fence }}$ & $r_{\text {Ride }}$ & r Combined \\
\hline $0.28^{*}$ & $0.41^{\text {* } * k}$ & $0.67^{*}$ * & $0.55^{*}$ 水 \\
\hline
\end{tabular}

TABLE 2.

Performance (average \pm SD) during the combined event and the isolated running and shooting sessions for the top third, the middle third and the bottom third competitors of the combined event.

Significantly different from the top third pentathletes of the combined event, $P<0.05$. 
\# Significantly different between middle third pentathletes of the combined event and bottom one, $\mathrm{P}<$ 0.05 .

\begin{tabular}{|c|c|c|c|c|c|c|c|}
\hline & \multirow{2}{*}{$\begin{array}{l}\text { Overall } \\
\text { combined } \\
\text { event } \\
\text { performance }\end{array}$} & \multicolumn{2}{|c|}{$\begin{array}{l}\text { Running } \\
\text { performance }\end{array}$} & \multicolumn{3}{|c|}{ Shooting performance } & \multirow[t]{2}{*}{$\begin{array}{l}\text { Transition } \\
\text { time }\end{array}$} \\
\hline & & $\begin{array}{l}\text { Total } \\
\text { running } \\
\text { time }\end{array}$ & $\begin{array}{l}\text { Running } \\
\text { speed }\end{array}$ & $\begin{array}{l}\text { Total } \\
\text { shooting } \\
\text { time }\end{array}$ & $\begin{array}{l}\text { Overall } \\
\text { shooting } \\
\text { accuracy }\end{array}$ & $\begin{array}{l}\text { Delay } \\
\text { per } \\
\text { attempt }\end{array}$ & \\
\hline $\begin{array}{l}\text { Top third } \\
\text { pentathletes }\end{array}$ & $695 \pm 10 \mathrm{sec}$ & $\begin{array}{l}551 \pm \\
11 \mathrm{sec}\end{array}$ & $\begin{array}{l}18.2 \pm \\
0.4 \\
\mathrm{~km} \cdot \mathrm{h}^{-1}\end{array}$ & $\begin{array}{l}86 \pm 16 \\
\text { sec }\end{array}$ & $79 \pm 13 \%$ & $\begin{array}{l}4.5 \pm \\
0.4 \mathrm{sec}\end{array}$ & $58 \pm 5 \mathrm{sec}$ \\
\hline $\begin{array}{l}\text { Middle } \\
\text { third } \\
\text { pentathletes }\end{array}$ & $714 \pm 7 \mathrm{sec}^{\star}$ & $\begin{array}{l}549 \pm \\
20 \mathrm{sec}\end{array}$ & $\begin{array}{l}18.2 \pm \\
0.6 \\
\mathrm{~km} \cdot \mathrm{h}^{-1}\end{array}$ & $\begin{array}{l}109 \pm \\
19 \mathrm{sec}^{*}\end{array}$ & $68 \pm 12 \%{ }^{*}$ & $\begin{array}{l}5.0 \pm \\
0.7 \mathrm{sec}\end{array}$ & $56 \pm 5 \mathrm{sec}$ \\
\hline $\begin{array}{l}\text { Bottom } \\
\text { third } \\
\text { pentathletes }\end{array}$ & $\underset{* \#}{741} \pm 25 \mathrm{sec}$ & $\begin{array}{l}564 \mathrm{sec} \\
\pm 11 \\
\sec \end{array}$ & $\begin{array}{l}17.7 \pm \\
0.3 \\
\mathrm{~km} \cdot \mathrm{h}^{-1}\end{array}$ & $\begin{array}{l}117 \pm \\
23 \mathrm{sec}\end{array}$ & $64 \pm 10 \%{ }^{*}$ & $\begin{array}{l}5.0 \pm \\
0.4 \mathrm{sec}\end{array}$ & $60 \pm 5 \mathrm{sec}$ \\
\hline
\end{tabular}

FIGURE 1.

Running velocity (average \pm SD, km.h-1) over each lap for the top third pentathletes, the middle third pentathletes and the bottom third pentathletes of the combined event (CE).

Significantly different from the lap1 $(\mathrm{p}<0.05)$.

$\$$ Significantly different from the lap2 $(\mathrm{p}<0.05)$.

\# Significantly different from middle third pentathletes of the combined event $(\mathrm{p}<0.05)$.

No significant difference with the top third pentathletes of the combined event $(\mathrm{p}<0.05)$. 


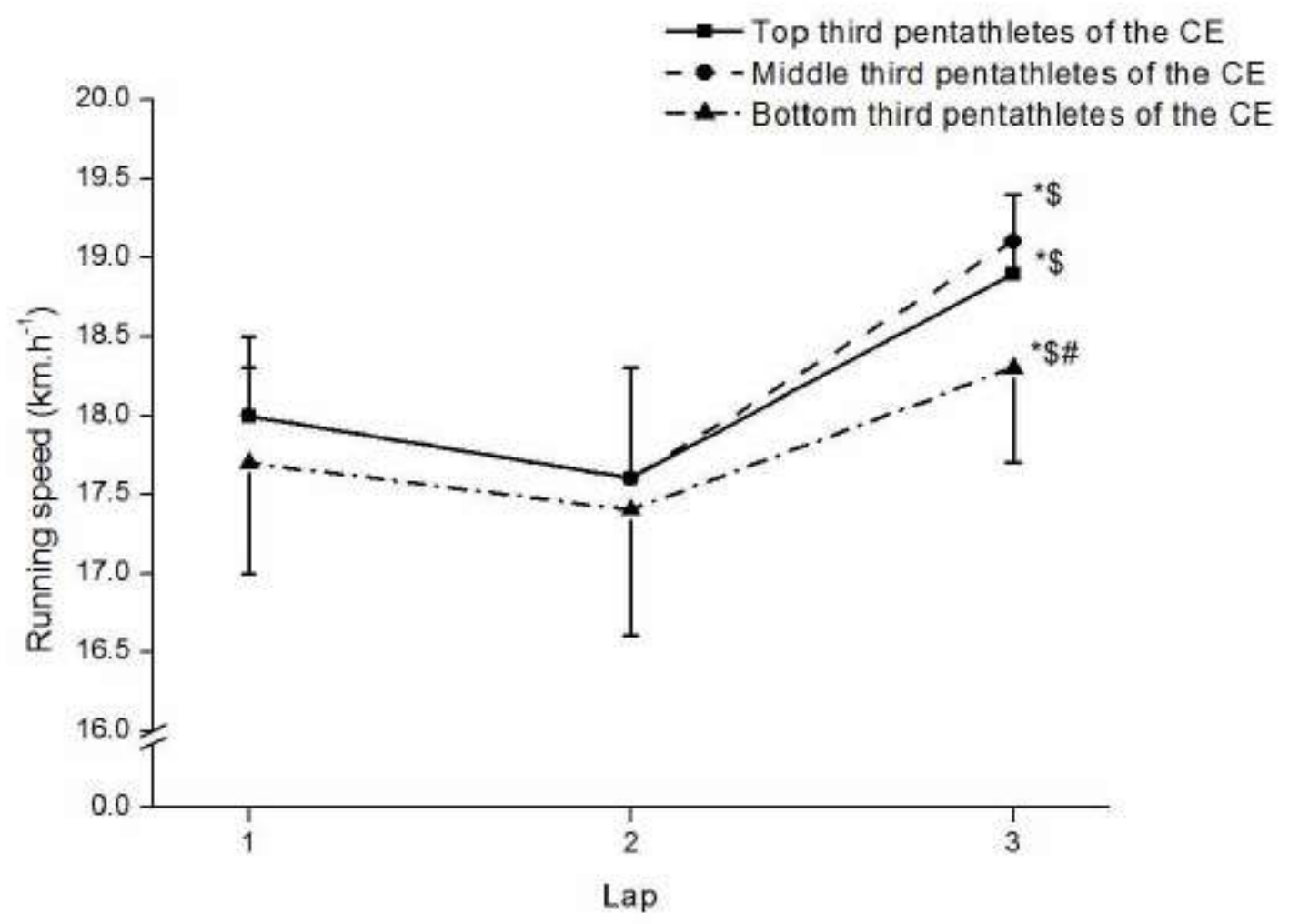

FIGURE 2.

Running velocity (average \pm SD, km.h-1) over each run sections for the top third pentathletes, the middle third pentathletes and the bottom third pentathletes of the combined event (CE).

* Significantly different from the previous section $(\mathrm{p}<0.05)$.

$£$ Significantly different from top third pentathletes of the combined event $(\mathrm{p}<0.05)$.

\# Significantly different from middle third pentathletes of the combined event $(\mathrm{p}<0.05)$. 


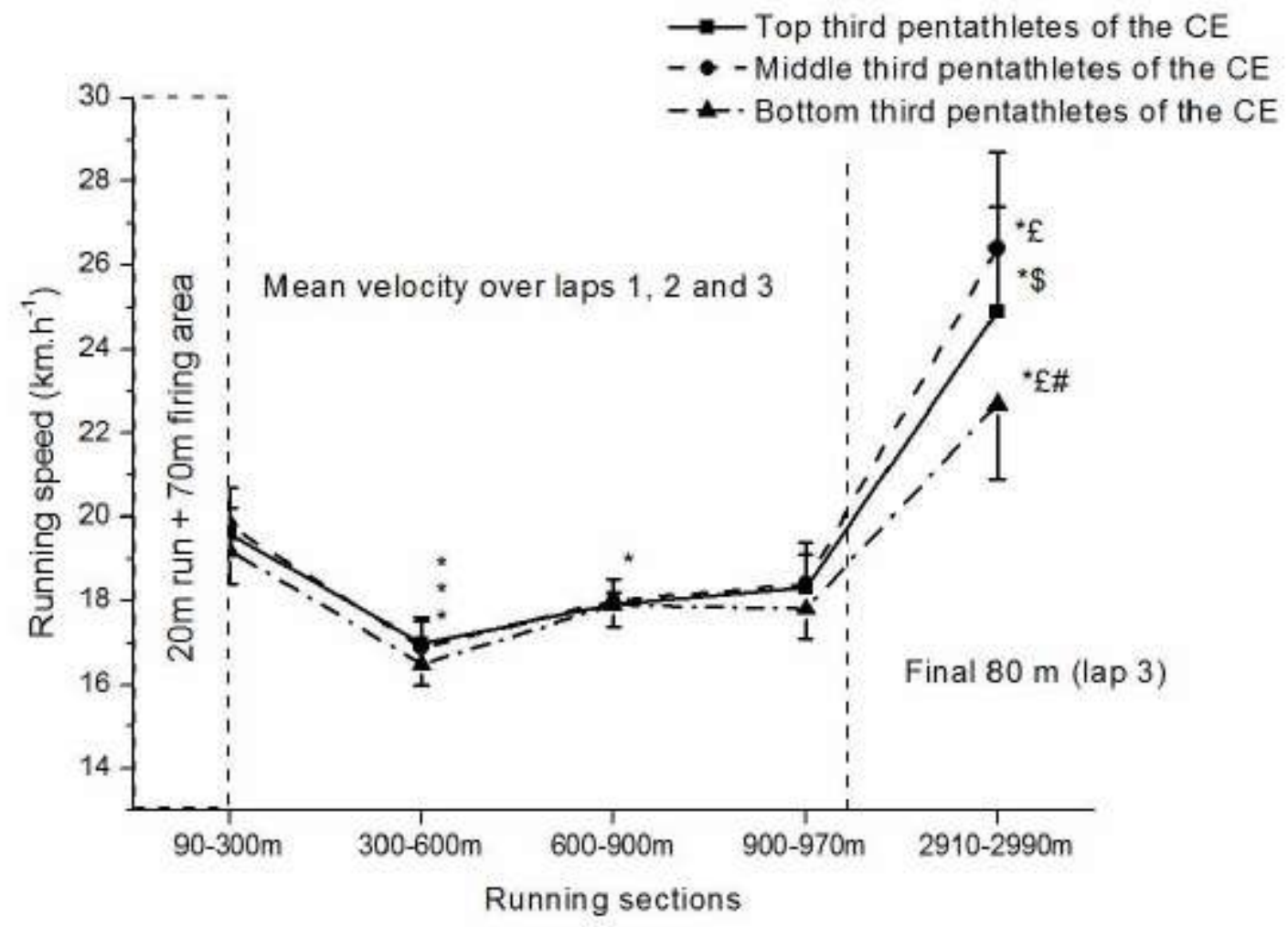

FIGURE 3.

Number of shots to make 5 targets down (average $\pm \mathrm{SD}$ ) during each shooting session for the top third pentathletes, the middle third pentathletes and the bottom third pentathletes of the combined event (CE).

* Significantly different from shooting session $1(\mathrm{p}<0.05)$.

$\$$ Significantly different from shooting session $2(\mathrm{p}<0.05)$.

$£$ Significantly different from top third pentathletes of the combined event $(\mathrm{p}<0.05)$. \# Significantly different from middle third pentathletes of the combined event $(\mathrm{p}<0.05)$. 


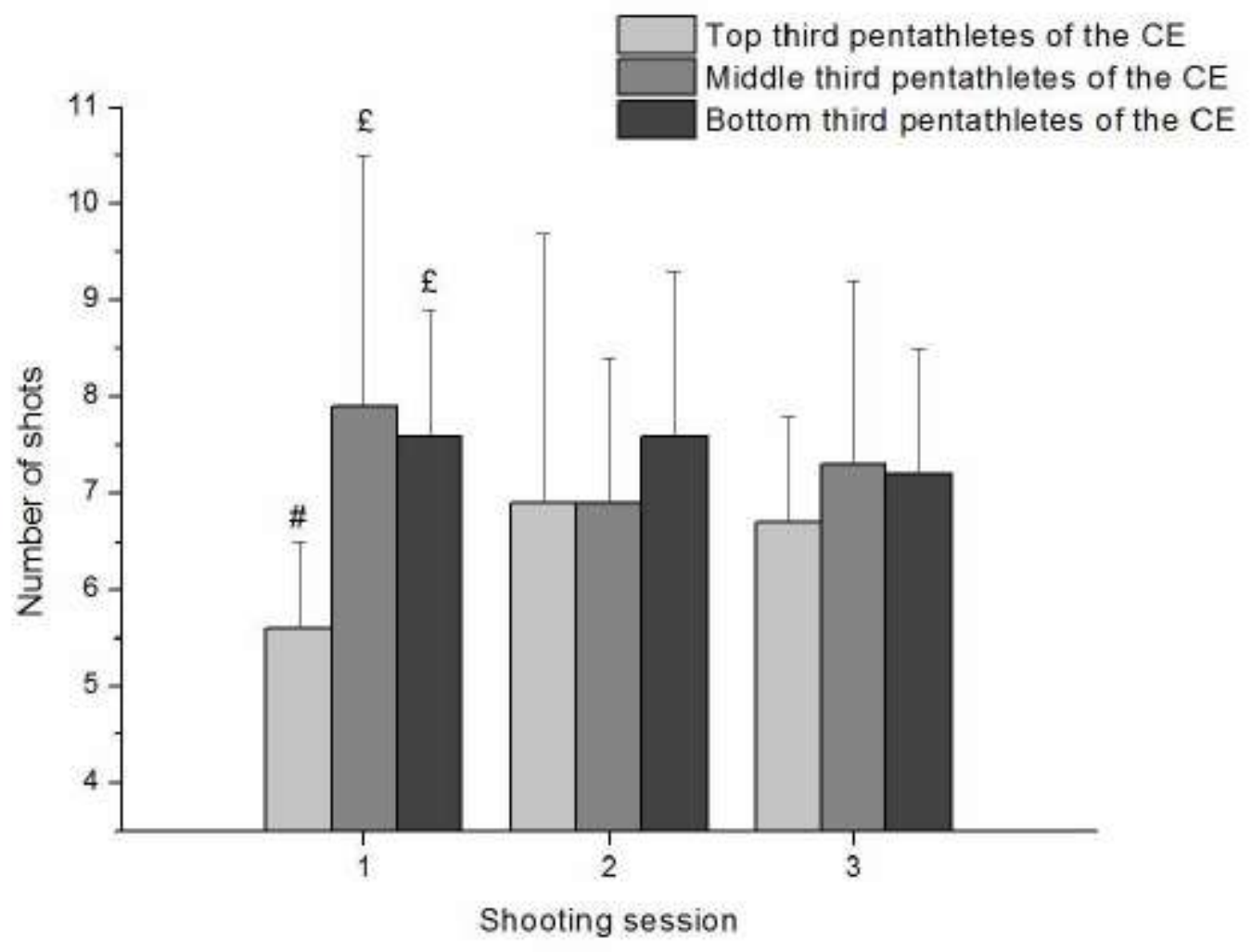

